\title{
Phosphoenolpyruvate in Rat Pancreatic Islets: a Possible Intracellular Trigger of Insulin Release?
}

\author{
M. C. Sugden and S. J.H. Ashcroft \\ Department of Clinical Biochemistry, Radcliffe Infirmary, Oxford, England
}

Summary. The content of phosphoenolpyruvate (PEP) has been measured in isolated rat islets of Langerhans incubated in vitro. Islet PEP was higher in islets incubated with $16.7 \mathrm{mmol} / 1$ glucose than in islets incubated with zero or $2.8 \mathrm{mmol} / 1$ glucose. Islet PEP content was also increased in islets incubated with $5 \mathrm{mmol} / \mathrm{l} \mathrm{D}$-glyceraldehyde. Mannoheptulose abolished the glucose-induced rise in PEP content but not that elicited by D-glyceraldehyde. These results are consistent with a role for PEP as an intracellular mediator of glucose- and glyceraldehyde-induced insulin release. The kinetics of pyruvate kinase in extracts of rat islets were studied. The maximal extractable activity was considerably higher than known rates of glycolytic flux. The Km values were found to be $0.16 \mathrm{mmol} / \mathrm{I}$ for PEP and $0.5 \mathrm{mmol} / 1$ for ADP. The control of islet PEP content and the possible role of PEP in insulin release are discussed.

Key words: Islets of Langerhans, insulin, glucose, glyceraldehyde, phosphoenolpyruvate, glucoreceptor, substrate-site, regulator-site, pyruvate kinase, mannoheptulose.

Studies of the mechanism whereby the $\beta$-cells of the islets of Langerhans respond to increasing levels of blood glucose with increasing rates of insulin release and biosynthesis have been conducted within the conceptual framework of the regulator-site and the substrate-site models first proposed by Randle et al. [1] and later extended by Ashcroft et al. [2] to include a dual-site mechanism. The regulator-site model envisages that combination of glucose directly with a membrane glucoreceptor initiates changes leading ultimately to insulin release; the substratesite model proposes that changes in extracellular glucose concentration lead to changes in rates of metabolism of glucose to a key metabolic intermediate that acts as an intracellular modifier of the rate of insulin release. With the recent demonstration that pancreatic islet glucose metabolism shows the same anomeric specificity as that demonstrated for insulin release and other glucose-sensitive parameters of islet function [3], current evidence presents a strong case for the view that the insulin response to glucose may be mediated, at least in part, by a glucose metabolite, in accordance with the substrate-site model. However, the identity of the key glucose metabolite(s) is totally unresolved; such a metabolite should change in concentration in response to changes in extracellular glucose concentration and also be capable of interacting with the release system. Of glucose metabolites so far studied, only glucose 6-phosphate and phosphoenolpyruvate (PEP) have been suggested to be perhaps capable of such interaction by modifying (i) insulin release from an artificially reconstructed in vitro release system [4], and (ii) the activity of islet adenylate cyclase [5]. Islet glucose 6-phosphate content has been shown to increase rapidly in mouse or rat islets in response to an increased glucose concentration [6] and to achieve a steady state level bearing a sigmoidal relationship to extracellular glucose concentration [7]. However, glyceraldehyde-stimulated insulin release [2] is unlikely to be mediated by changes in islet glucose 6-phosphate content as fructose diphosphatase activity has not been detected in islets. In this study we have therefore investigated the possible importance of PEP as an intracellular trigger of insulin release. 


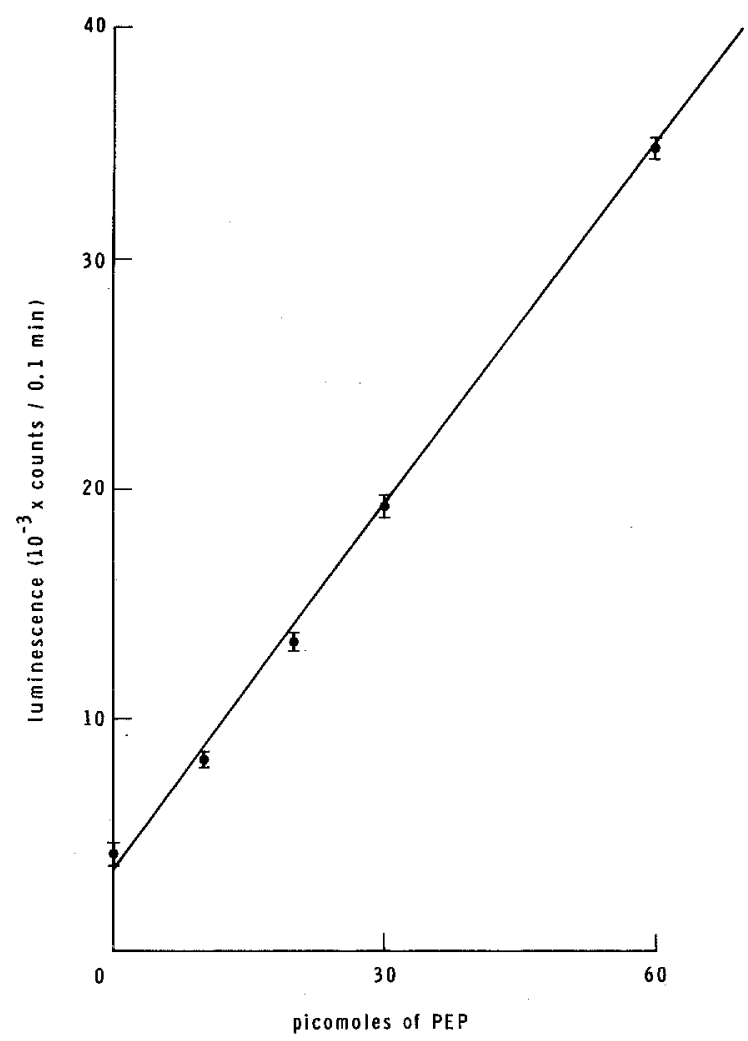

Fig. 1. Standard curve for PEP using the luciferase method: ATP was generated from PEP using pyruvate kinase and ADP as described in the text. Each point is the mean ( \pm SEM) of 4 determinations

\section{Materials and Methods}

\section{Reagents}

Firefly luciferase, bovine albumin and D-glyceraldehyde were from Sigma Chemical Co. Other enzymes, PEP (cyclohexylammonium salt) and coenzymes were from Boehringer. Other chemicals were from British Drug Houses and were of the purest grade obtainable.

\section{Preparation of Islets}

Islets were prepared by a collagenase method [8] from the pancreases of $200-300 \mathrm{~g}$ male albino Wistar rats fed ad libitum on standard laboratory diet.

\section{Incubation of Islets}

Batches of 5-25 islets were incubated for 1 hour at $37^{\circ} \mathrm{C}$, in $30 \mu \mathrm{l} \mathrm{Krebs-bicarbonate} \mathrm{medium} \mathrm{[9]} \mathrm{con-}$ taining albumin $(2 \mathrm{mg} / \mathrm{ml})$ and glucose or other additions as stated in the text or tables. Metabolism was arrested by the addition of $30 \mu \mathrm{l}$ ice-cold 0.1 $\mathrm{mol} / \mathrm{l} \mathrm{HCl}$ and the islets were disrupted by sonication $(3 \times 5$ secs at No. 1 on a Dawe Soniprobe). 45 $\mu \mathrm{l}$ sonicate were added to $50 \mu \mathrm{l} 200 \mathrm{mmol} / \mathrm{l}$ triethanolamine buffer $\mathrm{pH} 7.4$ containing $10 \mathrm{mmol} / \mathrm{l}$ $\mathrm{MgSO}_{4}, 200 \mathrm{mmol} / 1 \mathrm{KCl}$ and $1 \mathrm{mmol} / \mathrm{l}$ EDTA (all subsequent additions were made in this buffer), immediately heated in a boiling-water bath for $5 \mathrm{~min}$ utes and then cooled to room temperature. This method of neutralisation of the sonicate did not reactivate pyruvate kinase.

\section{Assay of PEP}

Principle: PEP was assayed as ATP produced by the reaction $\mathrm{PEP}+\mathrm{ADP} \rightarrow$ pyruvate $+\mathrm{ATP}$, after removal of endogenous ATP by the reaction ATP + glucose $\rightarrow \mathrm{ADP}+\mathrm{G} 6 \mathrm{P}$.

Procedure: To the islet extract were added $5 \mu 1$ ADP $\left(10^{-4} \mathrm{mmol} / \mathrm{l}\right)$ and $5 \mu \mathrm{l}$ hexokinase (1.4 units); to extracts of islets incubated in the absence of glucose, $5 \mu \mathrm{l} 20 \mathrm{mmol} / \mathrm{l}$ glucose were also added. ADP required for the pyruvate kinase step was added at this stage so that any contaminating ATP was removed. The extracts were then incubated at $26^{\circ}$ for 45 minutes to allow the complete conversion of ATP present to ADP by hexokinase in the presence of excess glucose. The extracts were boiled for 5 minutes and then $30 \mu \mathrm{l}$ were removed for assay by the luciferase system (see below) to verify removal of ATP. To the remainder of the extracts were added $5 \mu l$ pyruvate kinase ( 0.6 units); conversion of PEP to pyruvate and the concomitant conversion of ADP to ATP was allowed to proceed to completion $\left(15 \min\right.$ at $\left.26^{\circ}\right)$.

ATP in samples and blanks was measured by the luminescence produced by firefly luciferase $[10]$ using a scintillation counter as detector. The time passing from addition of the luciferase until the start of the counting was accurately standardized by always adding the luciferase when the printing out of the result for the preceding tube started. An Isocap scintillation counter (Searle Instruments), operated at room temperature, was used. The photo-multipliers were switched out of coincidence and each sample was counted for 0.1 minutes. Standard ATP samples $(0-25 \mathrm{pmol})$ were always included. Islet PEP content was calculated as follows: the apparent PEP content of islet extract was read from standard curves of PEP samples $(0-60 \mathrm{pmol})$ in incubation media taken through the whole procedure. The luminescence observed in islet extracts not treated with pyruvate kinase and in PEP samples in incubation media, also not treated with pyruvate kinase, 
Table 1. Effects of glucose, glyceraldehyde and mannoheptulose on islet PEP content

\begin{tabular}{|c|c|c|c|c|}
\hline Line & Additions to medium & $\begin{array}{l}\text { pmol PEP per islet } \\
(\text { mean } \pm \text { SEM })\end{array}$ & $\begin{array}{l}\text { No. of } \\
\text { observations }\end{array}$ & Significance \\
\hline 1. & None & $0.767 \pm 0.046$ & 26 & - \\
\hline 2. & $2.8 \mathrm{mmol} / 1 \mathrm{D}$-glucose & $0.859 \pm 0.055$ & 31 & $\mathrm{p}>0.05$ vs. 1 (N.S) \\
\hline 3. & $16.7 \mathrm{mmol} / 1 \mathrm{D}$-glucose & $1.189 \pm 0.046$ & 62 & $\mathrm{p}<0.001$ vs. 1 or 2 \\
\hline 4. & $5 \mathrm{mmol} / 1 \mathrm{D}$-glyceraldehyde & $1.203 \pm 0.092$ & 27 & $\mathrm{p}<0.001$ vs. 1 \\
\hline 5. & $16.7 \mathrm{mmol} / 1 \mathrm{D}$-glucose + & & & \\
\hline & $14.3 \mathrm{mmol} / \mathrm{l} \mathrm{D}$-mannoheptulose & $0.794 \pm 0.096$ & 12 & $\mathrm{p}<0.001$ vs. 3 \\
\hline 6. & $\begin{array}{c}5 \mathrm{mmol} / 1 \mathrm{D} \text {-glyceraldehyde }+ \\
14.3 \mathrm{mmol} / 1 \mathrm{D} \text {-mannoheptulose }\end{array}$ & $1.627 \pm 0.210$ & 12 & $\mathrm{p}<0.05$ vs. 4 \\
\hline
\end{tabular}

Batches of $5-25$ islets were incubated at $37^{\circ}$ for $60 \mathrm{~min}$ in $30 \mu \mathrm{l} \mathrm{Krebs}$ bicarbonate medium containing albumin $(2 \mathrm{mg} / \mathrm{ml})$ and the additions shown. After incubation, islet metabolism was arrested by the addition of $30 \mu \mathrm{I} 0.1 \mathrm{~mol} / \mathrm{l} \mathrm{HCl}$. The islets were disrupted by sonication and the concentration of PEP in the sonicate was measured as described in the text. Statistical significance of differences were assessed using Student's t-test

was then used to correct for the contribution to the apparent islet PEP content of residual islet ATP, and ATP and PEP in the pyruvate kinase.

\section{Assay of Islet Pyruvate Kinase}

Batches of 200-300 islets harvested in $20 \mu \mathrm{l}$ bicarbonate medium were disrupted by sonication as above after adding 200-300 $\mu \mathrm{l}$ ice-cold triethanolamine-buffer $(200$ or $50 \mathrm{mmol} / \mathrm{l}) \mathrm{pH} 7.2 \mathrm{con}$ taining albumin $(1 \mathrm{mg} / \mathrm{ml}), \mathrm{MgSO}_{4}(10 \mathrm{mmol} / \mathrm{l})$, $\mathrm{KCl}(200 \mathrm{mmol} / \mathrm{l})$ and EDTA $(1 \mathrm{mmol} / \mathrm{l})$. Pyruvate kinase was assayed spectrophotometrically at $30^{\circ}$ $C$ by the decreased absorbance at $340 \mathrm{~nm}$ in $1 \mathrm{~cm}$ light path cuvettes containing $0.5 \mathrm{ml}$ triethanolamine buffer, as above, NADH $\left(3 \times 10^{-4}\right.$ $\mathrm{mol} / \mathrm{l}), \operatorname{ADP}\left(5 \times 10^{-5}-5 \times 10^{-3} \mathrm{~mol} / \mathrm{l}\right), \operatorname{PEP}(5$ $\left.\times 10^{-5}-1.5 \times 10^{-3} \mathrm{~mol} / \mathrm{l}\right)$, lactate dehydrogenase $(0.5$ units). Reaction rates were recorded on a Servoscribe chart-recorder, chart width $20 \mathrm{~cm}$, speed $30 \mathrm{~mm} / \mathrm{min}$, full scale deflection corresponding to an absorbance of 0.1 . No oxidation of NADH was observed in the absence of PEP or ADP. The reaction was linear with time and its rate proportional to the amount of islet extract added. Fresh islet extracts were always used. Because of the small amounts of experimental material available only one determination of enzyme activity was made at each concentration of PEP and ADP. However the experiments were repeated several times with quantitatively similar results.

\section{Results}

\section{Assay of Islet PEP}

Since islet PEP content was determined from standard curves constructed using authentic PEP taken through the same procedure, no routine corrections were needed for recovery. However, estimation of recovery of PEP standards by comparison with ATP standards indicated $100 \%$ recovery. A typical standard curve for PEP is shown in Figure 1. The intercept on the ordinate is due to ATP contaminating the pyruvate kinase.

The major technical problem encountered in this study was the apparently incomplete removal of islet ATP by the hexokinase/glucose method, although ATP in incubation medium alone was completely converted to ADP, as was ATP added to islet sonicates. It appeared as if a certain small amount of ATP in islet extract was assayable by luciferase, but not removable by hexokinase/glucose. This residual ATP was proportional to the number of islets in the extract and also appeared higher in extracts of islets incubated with the higher glucose concentration $(0.5$ pmols/islet in islets incubated with $2.8 \mathrm{mmol} / \mathrm{l} \mathrm{glu-}$ cose and 0.8 pmols/islet in islets incubated with 16.7 $\mathrm{mmol} / \mathrm{l}$ glucose). For this reason the procedure described above in which a sample of each islet extract was assayed for ATP after the hexokinase/glucose step, without addition of pyruvate kinase, was adopted.

\section{Islet Content of PEP; Effects of Glucose, Glyceraldehyde and Mannoheptulose}

Results are shown in Table 1 . The islet content of PEP was increased in islets incubated with 16.7 $\mathrm{mmol} / \mathrm{l}$ glucose compared with islets incubated with zero or $2.8 \mathrm{mmol} / 1$ glucose. This increase in PEP concentration was abolished by mannoheptulose $(14.2 \mathrm{mmol} / \mathrm{l})$. Islet content of PEP was also increased by D-glyceraldehyde $(5 \mathrm{mmol} / \mathrm{l})$, but this increase was not abolished by mannoheptulose; indeed, a tendency to higher levels of PEP was seen in islets incubated with mannoheptulose plus glycer- 

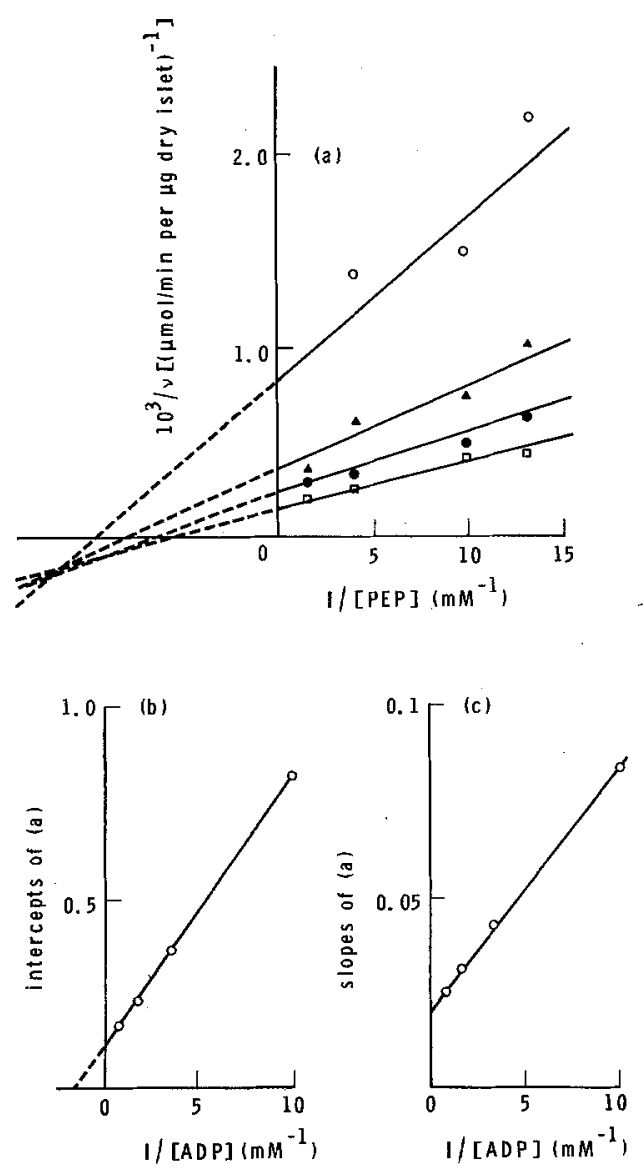

Fig. 2. Islet pyruvate kinase: effect of [PEP]: (a) A reciprocal plot for various concentrations of PEP in the presence of 0.1 (0), 0.3 $(\triangle), 0.6(\bullet)$ and $1.5(\sqsupset) \mathrm{mmol} / \mathrm{l} \mathrm{ADP}$. (b) The intercepts with the ordinate of the lines in (a) are plotted against 1/[ADP]. (c) The slopes of the lines in (a) are plotted against 1/[ADP]

aldehyde compared with islets incubated with glyceraldehyde alone. The PEP content of islets incubated in the absence of glucose was not significantly lower than that found in islets incubated with $2.8 \mathrm{mmol} / \mathrm{l}$ glucose.

\section{Islet Pyruvate Kinase}

The mean total activity of pyruvate kinase estimated at $30^{\circ} \mathrm{C}$ with $4 \mathrm{mmol} / 1 \mathrm{ADP}$ and $1.6 \mathrm{mmol} / \mathrm{PEP}$ was $5.4 \pm 0.72(\mathbf{n}=13) \mathrm{nmol} / \mathrm{min}$ per islet (equivalent to 10800 units/g dry islet assuming a mean islet dry weight of $0.5 \mu \mathrm{g}$ [7]). Lineweaver-Burk reciprocal plots of initial velocity against the concentration of either substrate at fixed concentrations of the other substrate were linear over the range of concentrations tested (Figs. $2 \mathrm{a}$ and $3 \mathrm{a}$ ). From the intercepts with the ordinates and slopes of such plots, secondary plots of intercept or slope vs. $1 /[\mathrm{ADP}]$ and $1 /[\mathrm{PEP}]$ were constructed (Figs. $2 \mathrm{~b}$ ), $2 \mathrm{c}, 3 \mathrm{~b}$, and $3 \mathrm{c}$ ) to determine the kinetic constants
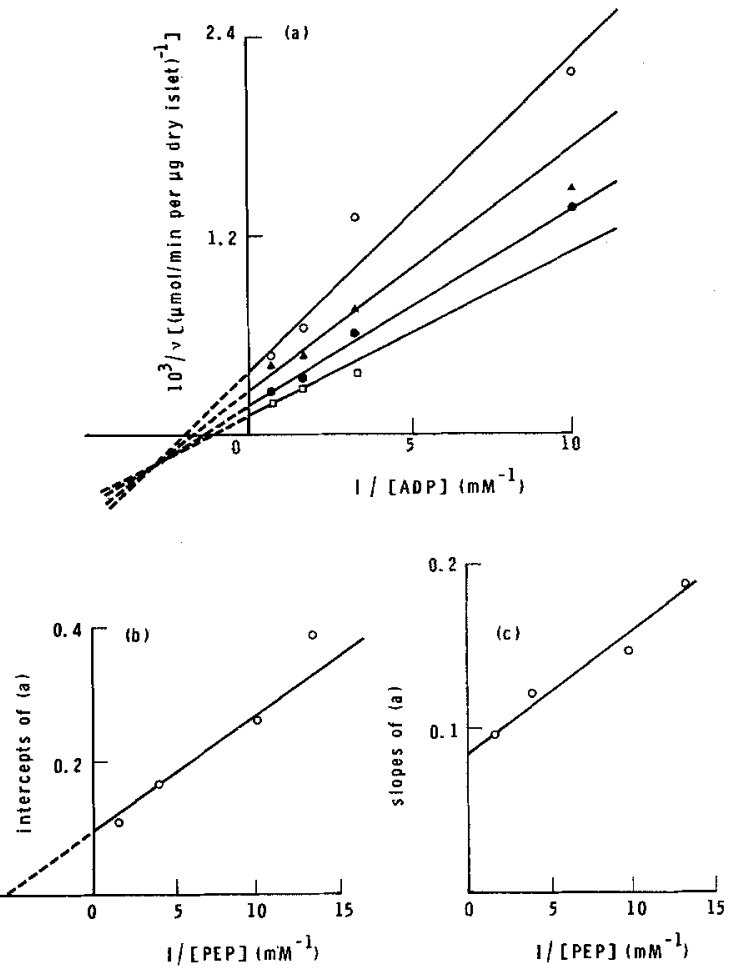

Fig. 3. Islet pyruvate kinase: effect of [ADP]: (a) A reciprocal plot for various concentrations of ADP in the presence of 0.075 $(0), 0.1(\triangle), 0.25(\bullet)$ and $0.6(\square) \mathrm{mmol} / 1 \mathrm{PEP}$. (b) The intercepts with the ordinate of the lines in (a) are plotted against $1 /[\mathrm{PEP}]$. (c) The slopes of the lines in (a) are plotted against $1 /[\mathrm{PEP}]$

[11]. $\mathrm{Km}$ values were calculated to be $1.6 \times 10^{-4}$ $\mathrm{mol} / \mathrm{l}$ for PEP, and $5 \times 10^{-4} \mathrm{~mol} / \mathrm{l}$ for ADP.

Since the kinetics of the $\mathrm{L}$-form of liver pyruvate kinase are modified by fructose 1:6 diphosphate [22] some islet homogenates were extensively dialysed prior to assay. No evidence for activation by fructose 1:6 diphosphate was found, either for dialysed or undialysed extracts.

The family of intersecting straight lines obtained in Lineweaver-Burk plots in Figures $2 \mathrm{a}$ and 3 a suggests that the ping-pong mechanism [11] is not applicable and this was confirmed by regression analysis fitting the data to the equations for singledisplacement and double-displacement (ping-pong) mechanisms for two-substrate reactions.

\section{Discussion}

The present study was prompted by the following considerations. Firstly, the striking parallels demon- 
strated between the metabolic and insulin-releasing activities of sugars, including chemical specificity, concentration dependence, anomeric specificity and effects of inhibitors $[2,3,6]$, provide strong support for the substrate-site hypothesis and hence for the possible existence of a key regulatory glucose metabolite. Secondly, measurements of changes in concentration of glycolytic intermediates in islets incubated with adrenaline, diazoxide, or in the absence of $\mathrm{Ca}^{++}$, have been interpreted as indicating the existence of a regulatory step for $\beta$-cell glycolysis, at or below the level of triosephosphate, of direct significance for control of insulin release [12]. Thirdly, in a novel in vitro system for studying insulin release, it was observed that PEP was capable of eliciting insulin release from $\beta$-granules incubated with islet membranes, ATP and $\mathrm{Ca}^{++}$; a number of other glycolytic intermediates were ineffective [4]. Fourthly, PEP has been found to be the only one of a number of glycolytic intermediates able to stimulate mouse islet adenyl cyclase [5]. Finally, in considering ways in which changes in the concentration of glucose metabolites could lead to the changes in $\beta$-cell cytosolic $\mathrm{Ca}^{++}$concentration, which current evidence suggests is the event most closely linked to exocytosis, observations on nonislet tissue have suggested a possible mechanism; uniquely among glycolytic intermediates, PEP, at concentrations of the same order as those found here in islets, has been found to stimulate $\mathrm{Ca}^{++}$efflux from isolated liver and heart mitochondria [13, 14].

In this study we have measured the content of PEP in isolated rat pancreatic islets incubated with glucose or glyceraldehyde to see whether PEP content can be correlated with the known effects of these carbohydrates on insulin release and islet metabolism. Raising the extracellular glucose from a non-stimulatory $(2.8 \mathrm{mmol} / \mathrm{l})$ to a stimulatory $(16.7 \mathrm{mmol} / \mathrm{l})$ concentration produced a significant elevation of islet PEP content. Mannoheptulose, which blocks glucose-stimulated insulin release [2] and islet glucose utilization [15], prevented the glucose-induced rise in PEP content. D-glyceraldehyde, which stimulates insulin release from rat or mouse islets $[2,16]$, also produced elevation of islet PEP content; mannoheptulose, which inhibits neither glyceraldehyde-stimulated insulin release nor glyceraldehyde oxidation by islets [2], did not reduce the glyceraldehyde-induced rise in PEP content. Indeed, somewhat higher levels of PEP were found in islets incubated with glyceraldehyde plus mannoheptulose compared with glyceraldehyde alone; the mechanism of this effect is unknown, but could possibly be explicable on the basis of impairment by mannoheptulose of glyceraldehyde me- tabolism subsequent to PEP formation; such an impairment has been noted in studies of pyruvate oxidation by mouse islets [17]. A tendency for mannoheptulose to potentiate glyceraldehyde-stimulated insulin release has also been reported $[2,18]$.

Thus these results are consistent with the hypothesis that PEP could mediate effects of glucose and glyceraldehyde on insulin release. Further substantiation of this hypothesis could come from more detailed studies of the concentration dependence, specificity and kinetics of carbohydrate-induced changes in PEP content.

The activity of pyruvate kinase in islet extracts was very high $(5.4 \pm 0.72(\mathrm{n}=13) \mathrm{nmol} / \mathrm{min}$ per islet $\equiv 10800$ units/g dry weight) compared with the maximal activity [20] of the other irreversible enzymes of glycolysis viz. hexokinase/glucokinase (38 units/g) and phosphofructokinase (5 units/g). This activity is similar in magnitude to that reported [21] for rat muscle-pyruvate/kinase (25700 units/g protein).

The theoretical flux (v) through the pyruvate kinase reaction (assuming irreversibility and Michaelis-Menten kinetics), if determined solely by substrate availability, can be calculated from the equation

$\frac{\mathrm{v}}{\mathrm{V}}=\frac{[\mathrm{PEP}][\mathrm{ADP}]}{\overline{\mathrm{K}}_{\mathrm{PEP}} \mathrm{K}_{\mathrm{ADP}}+\mathrm{K}_{\mathrm{ADP}}[\mathrm{PEP}]+\mathrm{K}_{\mathrm{PEP}}[\mathrm{ADP}]+[\mathrm{PEP}][\mathrm{ADP}]}$

where $V$ is the maximal velocity, $K_{P E P}$ and $K_{A D P}$ are the Michaelis constants for PEP and ADP, and $\bar{K}_{\mathrm{PEP}}$ is the dissociation constant for PEP.

At $16.7 \mathrm{mmol} / \mathrm{l}$ glucose, islet [PEP] was approximately $1.2 \mathrm{mmol} / 1$ (recalculated from Table 1 assuming a mean islet volume of $1 \mathrm{nl})$, [ADP] was taken to be $1.4 \mathrm{mmol} / \mathrm{l}$ (recalculated from data for mouse islets [23] and the values $\bar{K}_{\mathrm{PEP}}, \mathrm{K}_{\mathrm{ADP}} \& \mathrm{~K}_{\mathrm{PEP}}$ were determined [11] from Figures 2 and 3 to be $0.08,0.5$ and $0.16 \mathrm{mmol} / 1$ respectively: the calculated $\mathrm{V}$ was $1.8 \times 10^{-9} \mathrm{~mol}$ glucose equivalent $/ \mathrm{min}$ per islet. Measured glycolytic flux at $16.7 \mathrm{mmol} / \mathrm{I}$ glucose, however, is approximately $1.3 \times 10^{-12}$ $\mathrm{mol} / \mathrm{min}$ per islet at $37^{\circ}$ [2]. Moreover, in the absence of extracellular glucose, glycolytic flux estimated from the rate of lactate output drops to $<10^{-13} \mathrm{~mol} / \mathrm{min}$ per islet [7], whereas PEP concentration falls by only about $40 \%$ (Table 1 ). There is thus a discrepancy between observed and calculated fluxes via pyruvate kinase and also the maintenance of a high PEP concentration when glycolytic flux is low: these findings suggest that flux through pyruvate kinase in islets must be regulated by factors other than substrate concentration. The maintenance of PEP concentration when glycolytic flux is low could be explained by a substrate cycle between 
PEP and pyruvate using pyruvate kinase, phosphoenolpyruvate carboxykinase and pyruvate carboxylase. Pyruvate carboxylase has been found in islets [19], but it is not known if phosphoenolpyruvate carboxykinase is present. The activity of pyruvate kinase in the intact islet might be regulated by:

i) allosteric effectors. However, the inhibition of pyruvate kinase by a physiological concentration (5 $\mathrm{mmol} / \mathrm{l}$ ) of $\mathrm{ATP}-\mathrm{Mg}^{2+}$ was insufficient to account for the discrepancy between observed and calculated fluxes (M.C.S. unpublished observation). Furthermore the lack of effect of dialysis on the activity of pyruvate kinase suggests the absence of effectors in the islet extracts; no evidence for activation by fructose 1:6 diphosphate was observed.

ii) a phosphorylation/dephosphorylation cycle as in liver [24]

iii) compartmentation of the substrates. Pyruvate kinase is a cytosolic enzyme but PEP and ADP can occur in both mitochondria and cytosol, the former entering mitochondria via the tricarboxylate and adenine nucleotide carriers [14]. Thus if a substantial portion of islet PEP is mitochondrial, lower absolute concentrations and larger percentage changes in concentrations of PEP in the cytosol may occur than those reported here. There are no available data on points ii) and iii).

These studies have thus provided evidence consistent with a role for PEP in mediating glucose- and glyceraldehyde-stimulated release, but suggest that control of islet PEP content may be complex.

Acknowledgements. This work was supported by grants from the Medical Research Council and the British Diabetic Association.

\section{References}

1. Randle, P.J., Ashcroft, S. J.H., Gill, J.R.: In: F. Dickens, P.J. Randle, W.J. Whelan (Eds.): Carbohydrate Metabolism and its Disorders, Vol. 1, pp. 427-447. London: Academic Press 1968

2. Ashcroft, S. J.H., Weerasinghe, L. C. C., Randle, P. J.: Interrelationships of islet metabolism, adenosine triphosphate content and insulin release. Biochem. J. 132, 223-231 (1973)

3. Malaisse, W. J., Sener, A., Koser, M., Herchuelz, A.: Stimulus-secretion coupling of glucose-induced insulin release. Metabolism of $\alpha-$ and $\beta-D$ glucose in isolated islets. J. Biol. Chem. 251, 5936-5943 (1976)

4. Davis, B., Lazarus, N. R.: An in vitro system for studying insulin release caused by secretory granules - plasma membrane interactions; definition of the system. J. Physiol. (Lond.) 256, 709-729 (1976)

5. Capito, K., Hedeskov, C.J.: The effect of glucose, glucose metabolites and calcium ion on adenylate cyclase activity in homogenates of mouse pancreatic islets. Biochem. J. 162, 569-573 (1977)

6. Ashcroft, S.J.H., Capito, K., Hedeskov, C. J.: Time course studies of glucose-induced changes in glucose 6-phosphate and fructose 1:6 diphosphate content of mouse and rat pancreatic islets. Diabetologia 9, 299-302 (1973)
7. Ashcroft, S.J.H., Hedeskov, C.J., Randle, P.J.: Glucose metabolism in mouse pancreatic islets. Biochem. J. 118, 143-154 (1970)

8. Coll Garcia, E., Gill, J.R.: Insulin release by isolated pancreatic islets of the mouse incubated in vitro. Diabetologia $\mathbf{5}$, 61-66 (1969)

9. Krebs, H. A., Henseleit, K.: Untersuchungen über die Harnstoffbildung im Tierkörper. Hoppe Seylers Z. Physiol. Chem. 210, 33-66 (1932)

10. Stanley, P.E., Williams, S.G.: Use of the liquid scintillation spectrometer for determining adenosine triphosphate by the luciferase enzyme. Anal. Biochem. 29, 381-392 (1969)

11. Mahler, H.R., Cordes, E.H.: Biological Chemistry. New York: Harper \& Row 1966

12. Hellman, B.: Methodological approaches to studies on the pancreatic islets. Diabetologia 6, 110-120 (1970)

13. Chudapongse, P., Haugaard, N.: The effect of phosphoenolpyruvate on calcium transport by mitochondria. Biochem. Biophys. Acta 307, 599-606 (1973)

14. Sul, H.S., Shrago, E., Shug, A.L.: Relationship of phospoenolpyruvate transport, acyl coenzyme A inhibition of adenine nucleotide translocase and calcium ion efflux in guinea pig heart mitochondria. Arch. Biochem. Biophys. 172, 230-237 (1976)

15. Ashcroft, S.J.H., Weerasinghe, L.C.C., Bassett, J.M., Randle, P.J.: The pentose cycle and insulin release in mouse pancreatic islets. Biochem. J. 126, 525-532 (1972)

16. Ashcroft, S.J.H., Bassett, J.M., Randle, P.J.: Insulin secretion mechanisms and glucose metabolism in isolated islets. Diabetes 21 (Suppl. 2), 538-545 (1972)

17. Hedeskov, C.J., Hertz, L., Nissen, C.: The effect of mannoheptulose on glucose and pyruvate-stimulated oxygen uptake in normal mouse pancreatic islets. Biochim. Biophys. Acta 261, 388-397 (1972)

18. Hellman, B., Idahl, L. A., Lernmark, A., Sehlin, J., Taljedal, I. B.: The pancreatic B-cell recognition of insulin secretagogues. Comparisons of glucose with glyceraldehyde isomers and dihydroxyacetone. Arch. Biochem. Biophys. 162, 448-457 (1974)

19. Ashcroft, S. J. H., Randle, P. J.: Enzymes of glucose metabolism in normal mouse islets. Biochem. J. 119, 5-15 (1970)

20. Malaisse, W.J., Sener, A., Levy, J.: The stimulus secretion coupling of glucose-induced insulin release. Fasting-induced adaptation of key glycolytic enzymes in isolated islets. J. Biol. Chem. 251, 1731-1737 (1976)

21. Tanaka, T., Harano, Y., Sue, F., Morimura, H.: Crystallization, characterization and metabolic regulation of two types of pyruvate kinase isolated from rat tissues. J. Biochem. 62, 71-91 (1967)

22. Imamura, K., Taniuchi, K., Tanaka, T.: Multimolecular forms of pyruvate kinase. J. Biochem. 72, 1001-1015 (1972)

23. Wettermark, G., Tegner, L., Brolin, S. E., Borglund, E.: In: S. Falkmer, B. Hellmann, I. B. Taljedal (Eds.): The Structure and Metabolism of the Pancreatic Islets, pp. 275-282. Oxford: Pergamon Press. 1970

24. Ljungström, O., Hjelmquist, G., Engström, L.: Phosphorylation of purified rat liver pyruvate kinase by cyclic $3^{\prime}, 5^{\prime}-$ AMP-stimulated protein kinase. Biochim. Biophys. Acta 358, 289-298 (1974)

Received: February 7, 1977, and in revised form:

May 3, 1977

Dr. S.J.H. Ashcroft

Department of Clinical Biochemistry

Radcliffe Infirmary

Oxford

Great Britain 